
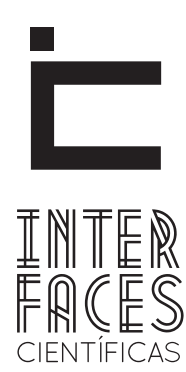

DIREITO

\title{
MEDIAÇÃO NA RESOLUÇÃO DE CONFLITOS SOCIAIS A PARTIR DO NOVO CÓDIGO DE PROCESSO CIVIL [LEl 13.105/2015]
}

\author{
MEDIATION IN THE RESOLUTION OF SOCIAL CONFLICTS FROM THE NEW CIVIL PROCESS CODE [LAW 13.105/2015] \\ MEDIACIÓN EN LA RESOLUCIÓN DE CONFLICTOS SOCIALES DEL NUEVO CÓDIGO DE PROCEDIMIENTO CIVIL (LEY 13.105/2015]
}

\section{RESUMO}

A mediação é um método alternativo inovador que visa à resolução de situações em que se constata a existência de um conflito de forma a garantir a paz social. Os conflitos são inerentes ao ser humano, uma vez que na sociedade coexistem diferentes pontos de vista sob uma mesma questão, bem como cada indivíduo é dotado de uma personalidade singular e subjetiva que o difere dos demais. Assim, por vezes, devido à complexidade presente nas relações humanas, os conflitos são levados a esfera judicial, que sobrecarregada não consegue solucioná-los em tempo hábil, definindo apenas o ganhador da causa. A mediação, por meio do auxílio de um mediador, revela- -se como um método eficaz e célere ao considerar os aspectos emocionais e priorizar um acordo satisfatório para ambas as partes. Neste sentido, este trabalho de natureza bibliográfica, adotará como meio de abordagem o método hipotético-dedutivo, a fim de assegurar uma melhor apreciação acerca da mediação de conflitos, abordando aspectos gerais e especificidades de alguns campos, como a mediação de conflitos familiares, escolares e organizacionais. Ainda, busca-se traçar as inovações trazidas pelo Novo Código de Processo Civil no que tange as fases aplicadas ao procedimento da mediação. Por meio deste estudo, foi possível verificar que a mediação desconstrói 
a visão negativa associada ao termo conflito, revelando que o mesmo traz consigo a oportunidade de crescimento e permite a identificação de aspectos disfuncionais que merecem ser investigados.

\section{ABSTRACT}

The mediation is an innovative alternative method that aims at resolving situations in which notes the existence of a conflict so as to guarantee social peace. The conflicts are inherent in the human being, once in society coexist different views under a same question as well as every individual is endowed with a unique personality and subjective that differs from the others. Sometimes, due to the complexity present in human relations, the conflicts are conducted judicial sphere, overcharged can't resolve in time enough and visa just set the winner of the cause. The mediation, through the assistance of a mediator, reveals itself efficient and fast when considering the emotional aspects and prioritise an agreement satisfactory to both parties. In this sense, this work of bibliographical, adopt as a means to approach the hy-

\section{RESUMEN}

La mediación es un método alternativo innovador que pretende resolver situaciones en las que se percibe un conflicto, con el fin de garantizar la paz social. Los conflictos son inherentes al ser humano, ya que en la sociedad coexisten diferentes puntos de vista sobre el mismo tema, así como cada individuo está dotado de una personalidad única y subjetiva que se diferencia de los demás. Así que, a veces, debido a la complejidad involucrada en las relaciones humanas, los conflictos son llevados a la esfera judicial que, sobrecargada, no puede resolverlos de una manera oportuna, solo creando una causa ganadora. La mediación, a través de la ayuda de un mediador, se revela como un método eficaz y rápido a considerar los aspectos emocionales y dar prioridad a un acuerdo satisfactorio para ambas partes. En este sentido, este trabajo bibliográfico, adopta como forma de abordar el método hipotético-

\section{PALAVRAS-CHAVE}

Conflito. Escola. Família. Mediação. Trabalho.

pothetical-deductive method, in order to ensure a better appreciation about conflict mediation, addressing general issues and specific in some fields, such as mediation of family, school and organizational conflicts. Still, it seeks to trace the innovations brought by the New $\mathrm{Ci}$ vil Procedure Code regarding the phases applied to the mediation procedure. Through this study, we found that mediation deconstructs the negative view associated with the term conflict, revealing that it brings with it the opportunity for growth and allows the identification of dysfunctional aspects that deserve to be investigated.

\section{KEYWORDS}

Conflict. School. Family. Mediation. Work.

-deductivo, con el fin de garantizar una mejor apreciación sobre la mediación de conflictos, abarcando aspectos y características específicas de ciertos campos generales, como la mediación de conflictos en la familia, escuela y organización. Además, se trata de trazar las innovaciones proporcionadas por el nuevo Código de Procedimiento Civil en relación con las fases aplicadas al procedimiento de mediación. A través de este estudio, encontramos que la mediación deconstruye la visión negativa asociada con el término conflicto, revelando que trae consigo la oportunidad para el crecimiento y permite la identificación de los aspectos disfuncionales que merecen ser investigados.

\section{PALABRAS CLAVE}

Conflicto. Escuela. Familia. Mediación. Trabajo. 


\section{INTRODUÇÃ̃O}

As situações de conflito surgem por diversos motivos e abrangem desde as divergências de opiniões e de objetivos até os valores e os princípios pessoais. Todavia, o conflito é inevitável e natural à vida humana, uma vez que cada ser humano possui características específicas e singulares que o difere dos demais indivíduos, havendo, assim, uma forte tendência para que existam posições antagônicas sobre uma mesma questão.

Dentre as distintas estratégias existentes para conduzir os conflitos, que podem ocorrer tanto na esfera familiar, quanto no ambiente escolar e organizacional, encontra-se a mediação. A mediação é uma tentativa de resolver os problemas enfatizando os interesses comuns e minimizando as diferenças entre os indivíduos em conflito.

0 método de mediar conflitos é fundamental em situações em que se constata a instauração de um impasse, sendo eficaz em encontrar a solução mais adequada e satisfatória para todos os envolvidos em um determinado conflito. Por conseguinte, o mediador desempenha um papel primordial, na medida em que possui características e funções necessárias à efetividade do procedimento, nas quais se destacam a credibilidade, a imparcialidade, a empatia e a confidencialidade.

Deste modo, este artigo de natureza bibliográfica, adotará como meio de abordagem o método hipotético-dedutivo, a fim de assegurar uma melhor apreciação acerca da mediação, buscando compreender os aspectos gerais e as especificidades dos conflitos existentes nos contextos familiar, escolar e organizacional, bem como aborda o método da mediação como uma alternativa inovadora para a resolução de impasses, destacando-se as alterações originadas através da Lei n 13.105/2015.

\section{CONFLITO EM DIFERENTES CONTEXTOS}

\subsection{CONCEITO DE CONFLITO}

Conflito "significa, no seu sentido etimológico, luta, combate, colisão, discussão” (BUITONI, 2007, p.
6), sendo capaz de se desenvolver por diversos motivos que envolvem incompatibilidades de múltiplas ordens. Segundo Deutsch (2004, p. 35), "uma ação incompatível com outra impede, obstrui, interfere, danifica ou de alguma maneira torna a última menos provável ou menos efetiva”. Chrispino (2007, p. 15) acrescenta que conflito é "toda opinião divergente ou maneira diferente de ver ou interpretar algum acontecimento".

Buitoni (2007, p. 6) destaca que "a vida sempre gerou conflitos entre as pessoas, e hoje se sabe, comprovadamente, até da pessoa consigo mesma, conflitos interiores". Logo, os conflitos são inerentes ao ser humano, uma vez que na sociedade coexistem diferentes opiniões e percepções acerca das mais variadas situações. Ademais, frente a um impasse, diferentes posicionamentos podem ser adotados pelos indivíduos, conforme revela Silva (2010, p. 9):

\begin{abstract}
A relação dos indivíduos, grupos e instituições com o(s) conflito(s) é, com frequência, uma relação pautada pela ocultação, fuga, medo, intimidação... Ou seja, uma reação predominantemente determinada e experienciada por parâmetros negativos ou evasivos que tendem a evitar os problemas, não os identificando, nem enfrentando de forma positiva.
\end{abstract}

O comportamento de evitação manifestado pelos indivíduos é considerado comum na medida em que conviver com a incompatibilidade tende a gerar certo incômodo e inquietude. Sabe-se que não é tarefa fácil aceitar as divergências de objetivos e de opiniões quando estas percorrem o caminho contrário dos valores e princípios pessoais. Assim, é neste contexto, marcado pela vivência individual e por posições antagônicas que emerge o conflito.

Por conseguinte, para que ocorra a dissolução de um conflito, torna-se necessário compreender a sua natureza e os elementos que fazem parte de sua constituição. Há diversas teorias e perspectivas que aludem sobre a estrutura do conflito. Para John Paul Lederach, mediador e conciliador que atua há mais de 20 anos em uma ampla gama de conflitos, 0 conflito deve ser compreendido pelas causas, pelos protagonistas e pelo processo; enquanto que para 
Xesús Jares, além desses três elementos existe um quarto, que abrange o contexto em que o conflito se produz (SILVA, 2010).

O conflito também pode ser subjetivo e objetivo. 0 primeiro envolve "os relacionamentos, as emoções, os pontos de vista e as percepções diferentes de cada participante, assim como as falhas na comunicação e na compreensão dos fatos" (VEZZULLA, 2004, p. 67). Já o segundo tipo de conflito abrange questões mensuráveis e concretas.

Ressalta-se a importância de se trabalhar com a emoção, por vezes ignorada, visto que ela é o ingrediente principal de todo conflito presente nas interações humanas. Além disso, "de grande importância, também, é a introdução de um método que procura substituir a imposição, o uso da força, a chantagem, o engano e a tentativa de tirar vantagens dentro do conceito ganha-perde de exclusão" (VEZZULLA, 2004, p. 68). Por meio de uma nova abordagem, o caráter negativo associado ao conflito pode ser substituído por uma visão positiva, marcada pela cooperação e pela oportunidade de crescimento, no qual ambas as partes podem ganhar. Buitoni (2007, p. 6) alude que "parece existir um potencial positivo no conflito, desde que o conflito não seja encarado de forma apenas lógica e racional, para culpar ou inocentar os litigantes".

Impera, portanto, a necessidade de novas metodologias para a resolução de conflitos, direcionadas para "uma co-participação responsável, que admite a singularidade de cada uma das partes envolvida no conflito, bem como a possibilidade de ganhar conjuntamente" (SANTOS; CUNHA, 2004, p. 80). A ocorrência de disputas entre cônjuges, filhos, vizinhos, colegas de escola e de trabalho, organizações, comunidades e afins sempre estarão presentes na sociedade, o que reforça a concepção de que o melhor meio de resolver satisfatoriamente um conflito é por meio do acordo.

\subsection{OS CONFLITOS FAMILIARES, ESCOLARES E OCUPACIONAIS}

A família é o componente principal de toda sociedade, na medida em que possui como responsabilidade a formação dos indivíduos. Segundo Falcke e Wagner
(2005, p. 26), "as relações estabelecidas com a família na qual se nasce são as mais importantes da vida e vão representar a base do comportamento futuro".

Quando a família permanece unida pelo afeto, os conflitos não necessitam ser solucionados pela esfera jurídica. Contudo, quando são "rompidos os laços de algum dos envolvidos - pai e mãe -, há consequências legais e afetivas para eles mesmos e seus filhos" (BRAGANHOLO, 2005, p. 72).

Neste sentido, a mediação familiar é uma opção para casos conflituosos, principalmente aqueles que envolvem divórcios e guardas dos filhos. Luz (2013, p. 73) explicita que "a finalidade da mediação familiar é eliminar disputas resolvendo desavenças através de um mecanismo alternativo, sem que sejam determinados às partes os ritos procedimentais como acontece na esfera judicial”. Ainda, Warat (2004, p. 33) complementa:

A mediação com sensibilidade introduz o amor como condição de vida, como uma forma de sentir e encontrar sentido para a vida. Isto é, o amor como dom supremo de senti-lo da existência. Por intermédio da mediação com sensibilidade se tentaria reintroduzir no conflito o amor.

Verifica-se que a utilização desse método permite restaurar os relacionamentos, bem como manter a função principal da família, que consiste na promoção do desenvolvimento saudável de seus membros. Deste modo, a mediação percorre um caminho marcado por princípios que buscam "expulsar os maus sentimentos e apostar em incluir bons acordos e a sensibilidade nas pessoas" (LUZ, 2013, p. 77), possibilitando que estejam mais preparadas para enfrentar novos e futuros conflitos inerentes à vida humana.

Em relação à escola, esta é "uma organização social com regras e normas próprias, constituída por uma diversidade de atores sociais que formam uma comunidade educativa - alunos/as, docentes, funcionário/as, diretores e administrativos, pais e encarregados de educação" (TOMÁS, 2010, p. 13). Esta instituição exerce um papel fundamental na sociedade, pois é responsável pela socialização e pela aprendizagem dos indivíduos. 
E assim como em qualquer ambiente que haja interação, na escola "as pessoas com diferenças perceptivas e de valores tem de coexistir em um ambiente que impõe normas de coleguismos e ao mesmo tempo abriga o autoritarismo" (MÜLLER, 2008, p. 109). Consequentemente, os conflitos na escola são variados, podendo ocorrer entre os próprios alunos, entre os próprios professores e/ou entre professores e alunos. Os conflitos entre alunos abrangem apelidos ofensivos, brincadeiras violentas e bullying. Já entre os professores, o conflito tende a ser motivado pela competição.

Rosenberg propõe a chamada Comunicação Não-violenta (CNV) para auxiliar nos casos conflituosos. Segundo o autor, "a CNV se baseia em habilidades de linguagem e comunicação que fortalecem a capacidade de continuarmos humanos, mesmo em condições adversas" (ROSENBERG, 2006, p. 21). A CNV utiliza os discursos de todos os envolvidos em um determinado conflito para capturar as necessidades mais profundas e possibilitar que os relacionamentos sejam percebidos sob um novo enfoque, melhorando o convívio social e criando alicerces para diálogos mais transformadores.

No que se refere às organizações, ressalta-se como diferencial a "atenção especial para o clima interno de trabalho, permeado pela qualidade do relacionamento entre as pessoas" (CORRADI, 2008, p. 185). De acordo com Pires e Macêdo (2006, p. 87) “é por meio da interação entre as pessoas que se definem os propósitos das organizações". O relacionamento no ambiente de trabalho é cercado de diferentes conexões, que abrangem desde os laços profissionais até os laços de amizades e afinidades. Entretanto, para que ocorra a efetivação destes laços, devem-se considerar as características individuais de cada trabalhador, uma vez que uns possuem uma maior habilidade e outros uma menor habilidade de administrar a convivência com seus pares.

Paralelamente, a prática profissional pode gerar mal-entendidos, desentendimentos, desconfianças e episódios de estresse e irritação. Segundo Spagnol e outros autores (2010, p. 804), "as situações de conflito surgem quando as pessoas se colocam em posições antagônicas, a partir das suas divergências de percepção e de ideias, sendo essas inevitáveis e necessárias à vida grupal”.

Salienta-se que é fundamental avaliar a motivação e objetivo dos indivíduos perante o conflito, pois estes fatores são determinantes para que haja uma maior colaboração e uma melhor comunicação com vistas à solução e à alteração do estado conflituoso. Afinal, conforme referem Jacobsen e Rodrigues (2002, p. 43), "a força das pessoas que integram a organização tem grande poder de pressão, tanto a favor, como contra a mudança".

A mediação vem, portanto, para somar ao evitar uma abordagem não assertiva e não cooperativa por meio do estabelecimento da harmonia entre cada indivíduo e contexto em que se verifica a existência de um conflito.

\section{A RESOLUÇÃO DE CONFLITOS SOCIAIS POR MEIO DO MÉTODO INOVADOR DA MEDIAÇÃO}

A elevada demanda de ações judiciais nos tribunais brasileiros, o aumento populacional, a multiplicação de conflitos na sociedade e a ampliação do acesso à Justiça acarretam um acúmulo de processos que, consequentemente, tornam o trâmite judicial moroso e, em alguns casos, incapaz de atender com presteza os interesses dos litigantes. Nesta perspectiva, diversos conflitos que, aparentemente, seriam de fácil resolução, permanecem sem uma resposta do judiciário por muitos anos, o que estimula o surgimento de novos desentendimentos entre as partes e, consequentemente, o nascimento de um círculo vicioso, no qual os envolvidos sequer identificam o seu estopim.

Cumpre ressaltar que diversos conflitos têm origem quando o ser humano, ao visualizar a opinião do outro como antagonista no meio social, vale-se da violência como forma justificada de impedir a proliferação deste posicionamento e garantir a satisfação do seu desejo individual. A partir disso, vislumbra-se a dificuldade de conviver e aceitar o diferente, o que 
gera uma sociedade baseada na exclusão e opressão estatal, requerendo uma intervenção capaz de impedir tamanho desatino. Deste modo, as novas formas de resolução de conflitos possuem um potencial inovador de transformar este cenário, fazendo com que seja minorada a perda de credibilidade no Poder Judiciário (SPENGLER; GIMENEZ, 2013).

Diante dos múltiplos motivos que suscitam o Judiciário a buscar soluções alternativas para atender à crescente demanda de conflitos levados aos tribunais, constata-se a necessidade de um instrumento célere e inovador para a resolução de conflitos. Assim, a mediação se apresenta como um método alternativo para a resolução de conflitos judiciais em distintos âmbitos sociais de forma pacificadora. Nas palavras de Müller (2007, p. 34), a “mediação é um processo no qual um terceiro imparcial facilita a resolução do conflito por meio da promoção de acordos voluntários entre ambos os envolvidos na contenda".

Além disso, a mediação permite a participação das partes na negociação de forma autônoma e ativa com o auxílio de um mediador, principalmente no que se refere a definição das regras que regerão o procedimento, admitindo-se que proponham soluções livremente, ainda que inapropriadas para a demanda ou inexequíveis, unicamente com o intuito de incentivar as partes a apresentar opções para a resolução do litígio.

A mediação apresenta uma nova proposta ao possibilitar a satisfação de ambos os participantes, permitindo com que dialoguem, proponham soluções para o conflito e, por fim, realizem um acordo com vistas ao alcance de um resultado positivo. Entretanto, ressaltase que a medição, em regra, não é obrigatória, sendo imprescindível que as partes envolvidas estejam dispostas a resolver a questão por este meio. A flexibilidade da mediação é o que garante a sua eficácia.

Finalmente, frente à importância de sua atuação, o mediador de conflitos necessita integrar conhecimentos de diferentes áreas para atingir resultados satisfatórios e responder às demandas sociais, o que justifica a função não ser exercida por nenhuma profissão específica. Assim, "resultam dessa coerência teórico-instrumental, habilidades e atitudes que contribuem na formação de um perfil profissional aperfeiçoado em mediação de conflitos" (MÜLLER, 2008, p. 115).

\section{A MEDIAÇÃO NA PERSPECTIVA DO NOVO CÓDIGO DE PROCESSO CIVIL [LEI № 13.105/2015]}

\section{O Novo Código de Processo Civil (Lei n 13.105/2015)} e a Lei $n^{0} 13.140 / 2015$, denominada como "Lei da Mediação”, apontam significativas considerações e modificações no procedimento aplicável a mediação. Anteriormente à edição das referidas normas, apenas a Resolução no 125/2010, do Conselho Nacional de Justiça, regulamentava o procedimento da mediação e da conciliação, o que confirma que o Novo Código de Processo Civil reconheceu os métodos autocompositivos como uma forma capaz de facilitar a resolução consensual dos litígios.

Neste sentido, a mediação tornou-se princípio do processo civil, visto que 0 artigo $3^{\circ}, \S 2^{\circ}$ e $\S 3^{\circ}$, do Novo Código de Processo Civil, estabelece que o Estado promoverá, sempre que possível, a solução consensual dos conflitos, além de que a conciliação, a mediação e outros métodos de solução consensual de conflitos, deverão ser estimulados por juízes, advogados, defensores públicos e membros do Ministério Público, inclusive no curso do processo judicial. Ainda, os princípios que regem a mediação estão dispostos no artigo 166, do Novo Código de Processo Civil, e no artigo $2^{\circ}$, da Lei $n^{0} 13.140 / 2015$, sendo eles a independência, a imparcialidade, autonomia da vontade, a confidencialidade, a oralidade, a informalidade, a decisão informada, a isonomia entre as partes, a busca de consenso e a boa-fé.

Importa esclarecer que as audiências de mediação e de conciliação ocorrerão nos centros judiciários de solução consensual de conflitos, sendo sua criação de competência dos tribunais. Em casos excepcionais, as audiências serão realizadas na sede do juízo. Neste sentido, destaca-se o posicionamento de Neves (2016, p. 817) no que tange a relevância dos referidos centros: 
Demonstrando a pouca confiança de que todos os tribunais criarão tais centros, o art. $334, \S 1^{\circ}$, do Novo CPC prevê a atuação necessária do conciliador ou mediador na audiência apenas onde houver esse sujeito, ou seja, onde estiver funcionando o centro judiciário de solução consensual de conflitos. Caso não exista tal centro, caberá ao próprio juiz da causa a realização da audiência.

Sobre as fases aplicadas ao procedimento da mediação com base nas alterações trazidas pelo Novo Código de Processo Civil, inova-se no sentido de que se faz necessário que o autor informe na petição inicial se há interesse ou não em solucionar o conflito por meio dos métodos autocompositivos, bem como, em caso positivo, defina qual dos procedimentos atende os seus interesses, quais sejam a mediação ou a conciliação.

No que tange a falta de indicação pelo autor de qual método corresponde ao seu interesse, deve-se advertir que o juiz poderá defini-lo, considerando-se, sempre, o procedimento mais adequado para a situação. Neste ínterim, o artigo 165, $\S 2^{\circ}$ e $\S 3^{\circ}$, do Novo Código de Processo Civil, prevê que a conciliação ocorrerá nos casos em que não houver vínculo anterior entre as partes e a mediação apenas quando existir o vínculo.

Assim, tendo a petição inicial preenchido todos os requisitos essenciais e não sendo o caso de improcedência liminar do pedido, bem como sendo possível aplicar à demanda os métodos de autocomposição, cabe ao juiz designar a audiência preliminar de mediação ou de conciliação, observado o prazo mínimo de trinta dias de antecedência, além de o réu ser citado pessoalmente com pelo menos vinte dias da realização do ato. Cumpre ressaltar que "a citação realizada com menos de 20 dias da realização da audiência é causa de nulidade, aplicando-se ao caso o princípio da instrumentalidade das formas, cabendo a decretação de nulidade apenas se ficar comprovado o prejuízo ao réu" (NEVES, 2016, p. 816).

0 réu, assim como o autor, não possuindo interesse na audiência de mediação ou de conciliação, deve demonstrar o seu desinteresse por meio de petição, apresentada com dez dias de antecedência, contados da data da audiência. Ainda, havendo litisconsórcio, o desinteresse na realização da audiência deve ser manifestado por todos os litisconsortes. Evidencia-se que

[...] como a audiência só não será realizada se a vontade de ambas as partes for nesse sentido, havendo na petição inicial o requerimento de sua realização, a postura do réu torna-se inútil, porque mesmo não querendo a realização da audiência dela não conseguirá se livrar. (NEVES, 2016, p. 774).

Ademais, nos casos em que o autor não se manifestou sobre a realização de um dos métodos autocompositivos, é possível que o réu suscite o seu cancelamento. Neste viés, "não há que se falar em preclusão temporal para a concordância do autor com a não realização da audiência, de forma que, mesmo não tendo se manifestado nesse sentido em sua petição inicial, poderá fazê-lo posteriormente" (NEVES, 2016, p. 775).

Neste sentido, nota-se que o legislador não impõe a realização da audiência quando diante da manifestação de ambas as partes se constate o desinteresse. Para Didier (2015, p. 625), a adoção deste posicionamento é coerente, pois "elimina a possibilidade de a audiência não se realizar porque apenas uma parte não a deseja, mas ao mesmo tempo respeita a vontade das partes no sentido de não querer a autocomposição”. Nesse caso, o réu terá o prazo de quinze dias para oferecer a sua contestação, contados do protocolo do pedido de cancelamento da audiência de conciliação ou de mediação apresentado pelo réu.

Ao haver a definição da audiência de mediação ou de conciliação, a intimação do autor para a audiência deverá se fazer por meio da pessoa de seu advogado. Salienta-se que no momento em que o oficial de justiça realizar o ato de comunicação que the couber às partes e estas demonstrarem interesse em realizar a audiência de conciliação ou de mediação, deverá certificar em mandado. Após devidamente certificada, o juiz ordenará a intimação da parte contrária para se manifestar, no prazo de cinco dias, sem prejuízo do andamento regular do processo, entendendo-se o silêncio como recusa, nos termos do artigo 154, inciso VI e parágrafo único, do Novo Código de Processo Civil. 
Atentar-se-á, também, para que a pauta das audiências de mediação ou de conciliação seja organizada com cautela para que se preserve o intervalo mínimo de vinte minutos entre o início de uma e o início da seguinte. A lei não definiu um número máximo de sessões de mediação ou de conciliação que poderão ser realizadas. Portanto, é admissível que ocorram tantas sessões quantas forem necessárias para que as partes encontrem a melhor solução para o litígio, desde que não sejam ultrapassados dois meses da data da primeira sessão e a sessão anterior demonstre a possibilidade de resolução do conflito. Nas sessões, as partes devem estar acompanhadas por seus advogados ou defensores públicos, a fim de que se preserve o conhecimento em relação aos direitos que detêm.

Na hipótese de o autor ou o réu não comparecerem injustificadamente à sessão, a ausência será considerada ato atentatório à dignidade da justiça e será sancionado com multa de até dois por cento da vantagem econômica pretendida ou do valor da causa, revertida em favor da União ou do Estado. Conforme explana Didier (2015, p. 626), "comparecer à audiência de conciliação ou mediação é um dever processual das partes”.

Ao final da audiência, o mediador ou o conciliador deverá reduzir a termo a autocomposição e remeter os autos ao juízo competente para que homologue o termo de autocomposição por meio de sentença de mérito, sendo o processo extinto com resolução de mérito. Caso a autocomposição não se concretize, o prazo para que o réu apresente sua defesa iniciará a partir da data da audiência, nos termos do artigo 335, inciso I, do Novo Código de Processo Civil.

\section{CONSIDERAÇÕES FINAIS}

Para obter êxito na intervenção em contextos marcados por animosidades, torna-se, inicialmente, necessário desconstruir a visão negativa associada ao termo conflito, visto que uma situação de impasse traz consigo a possibilidade de crescimento e denuncia a presença de aspectos disfuncionais que merecem ser investigados. Posteriormente, frente a um conflito, a utilização do método da mediação se revela como uma alternativa eficaz e inovadora ao possibilitar a transformação e a remoção do problema de forma a garantir a paz social.

As partes envolvidas encontram, por meio do auxílio de um mediador, a melhor solução para o problema de forma consensual e não de forma competitiva, na qual há como requisito um ganhador e um perdedor. $A$ função do mediador durante o procedimento assume um caráter eminentemente facilitador em prol do interesse comum, buscando atuar no sentido de encorajar a autonomia das partes na resolutividade do conflito vivenciado por meio do diálogo e da cooperação.

No que tange ao Novo Código de Processo Civil, verifica-se que o legislador inseriu a mediação no trâmite processual diante de sua eficácia e facilitação na resolução de litígios, que se apresenta de grande valia ao judiciário. Entretanto, não se deve vislumbrar a mediação apenas como uma alternativa de reduzir a morosidade dos processos judiciais, mas, também, como um meio capaz de resolver o conflito que levou as partes a buscarem o judiciário com vistas a restauração do vínculo até então rompido entre elas.

Neste sentido, a mediação é, em síntese, um exercício de amor ao próximo e de paciência, que viabiliza o acesso a soluções céleres e criativas, atinge as aspirações democráticas dos cidadãos e garante a satisfação mútua, revigorando os relacionamentos e, evitando futuras disputas judiciais. Logo, os benefícios da mediação não podem ser preteridos, tamanha a proporção que alcança quando devidamente exercida e explorada pelos seus operadores.

\section{REFERÊNCIAS}

BRAGANHOLO, B.H. Novo desafio do Direito de Família contemporâneo: a mediação familiar. Revista

Conselho da Justiça Federal, n.29, p.70-79, 2005.

BUITONI, A. A dogmática jurídica e a indispensável mediação. Jus Navigandi. Ano 12, n.1355, p.1-12), 2007. Disponível em: <http://jus.com. 
br/artigos/9619/a-dogmatica-juridica-e-aindispensavel-mediacao>. Acesso em: 2 jul. 2016.

CHRISPINO, A. Gestão do conflito escolar: da classificação dos conflitos aos modelos e mediação.

Ensaio: Avaliação e Políticas Públicas em

Educação, v.15, n.54, p.11-28, 2007.

CORRADI, E.M.; ZGODA, L.T.R.W.; PAUL, M.F.B. $O$ gerenciamento de conflitos entre a equipe de enfermagem. Cogitare Enfermagem, v.13, n.2, p.184-193, 2008.

DEUTSCH, M. A Resolução do Conflito: processos construtivos e destrutivos. In: AZEVEDO, A.G. (Org.).

Estudos em arbitragem, mediação e negociação. V.3. Brasília: Grupo de Pesquisa, 2004.

DIDIER JR., Fredie. Curso de direito processual civil: introdução ao direito processual civil, parte geral e processo de conhecimento. 17.ed. Salvador: Jus Podvim, 2015.

FALCKE, D.; WAGNER, A. A dinâmica familiar e o fenômeno da transgeracionalidade: definição de conceitos. In: WAGNER, A. Como se perpetua a família? A transmissão dos modelos familiares. Porto Alegre: EDIPUCRS, 2005. p. 25-45.

JACOBSEN, A.L.; RODRIGUES, M.M.B. Abordagem para lidar com a resistência humana frente a processos de mudança organizacional. Revista de Ciências da Administração, v.4, n.6, p.39-49, 2002.

\section{LUZ, J.F. A mediação como mecanismo na resolução} de conflitos na esfera familiar: um estudo do projeto Justiça Comunitária em Passo Fundo (RS). 2013. Dissertação (Mestrado em Direito) - Universidade Regional Integrada do Alto Uruguai e das Missões, Santo Ângelo, 2013.

MÜLLER, F.G. Competências profissionais do mediador de conflitos familiares. 2007. Dissertação
(Mestrado em Psicologia) - Universidade Federal de Santa Catarina, Florianópolis,SC, 2007.

MÜLLER, F.G. Competências profissionais do mediador de conflitos no contexto escolar. Revista Electrónica de Investigación y Docencia, n.1, p.107121, 2008.

NEVES, Daniel Amorim Assumpção. Manual de direito processual civil. 8.ed. Salvador: Jus Podvim, 2016.

PIRES, J.C.S.; MACÊDO, K.B. Cultura organizacional em organizações públicas no Brasil. Revista de Administração Pública, v.40, n.1, p.81-105, 2006.

ROSENBERG, M.B. Comunicação não-violenta: técnicas para aprimorar relacionamentos pessoais e profissionais. São Paulo: Ágora, 2006.

SANTOS, L.; CUNHA, P. A importância da mediação familiar em casos de separação e divórcio: alguns resultados preliminares. In: Vo Congresso Português de Sociologia, Actas dos ateliers do Vo Congresso Português de Sociologia. Braga: Universidade do Minho, 2004. p. 80-84.

SILVA, A.M.C. Conflito(s) e Mediação em Contextos Educativos. Revista Galego-Portuguesa de Psicoloxía e Educación.l, v.18, n.1, p.7-18, 2010.

SPAGNOL, C. A.; et al. Situações de conflito vivenciadas no contexto hospitalar: a visão dos técnicos e auxiliares de enfermagem. Revista Escola de Enfermagem USP, v.44, n.3, p.803-811, 2010.

SPENGLER, F.M.; GIMENEZ, C.P.C. O resgate da comunidade e o papel da mediação comunitária na sociedade globalizada e individualista. In: SPENGLER, F.M.; COSTA, M.M.M. (Org.). Mediação de conflitos e justiça restaurativa. Curitiba: Multideia, 2013.

VEZZULLA, J.C. A mediação de conflitos com adolescentes autores de ato infracional. 2004. 
Dissertação (Mestrado em Serviço Social)

- Universidade Federal de Santa Catarina, Florianópolis,SC, 2004.

Data da submissão: 16 de março de 2017

Avaliado em: 28 de março de 2017 (Avaliador A)

Avaliado em: 17 de abril de 2017 (Avaliador B)

Aceito em: 18 de abril de 2017
WARAT, L.A. Surfando na Pororoca: 0 oficio do mediador. Florianópolis: Fundação Boiteux, 2004.
1 Graduada em Direito pela Faculdade Meridional - IMED; Especialista em Direito Civil e Processo Civil pela Faculdade Meridional - IMED; Advogada. E-mail: arianefaverzani@outlook.com

2 Graduada em Psicologia pela Faculdade Meridional - IMED; Especialista em Avaliação e Diagnóstico Psicológico pela Faculdade Meridional - IMED; Psicóloga da Prefeitura Municipal de Marau/RS. E-mail: arielefl@outlook.com

3 Doutoranda em Ciências Sociais pela Universidade do Vale do Rio Dos Sinos - UNISINOS; Mestre em Direito pela Universidade Regional Integrada do Alto Uruguai e das Missões - URI; Docente no Centro de Ensino Superior Riograndense - CESURG).E-mail: jana_fl@hotmail.com 